\title{
Pengaruh Motivasi dan Kepuasan Kerja Terhadap Kinerja Pegawai Pada Dinas Pendidikan Kabupaten Tanjung Jabung Barat
}

\author{
Kasiyati Yunita Wulansari \\ Sekolah Tinggi Ilmu Ekonomi Graha Karya
}

\begin{abstract}
The title raised in this study is the Effect of Job Motivation and Satisfaction on Employee Performance at the Education Office of West Tanjung Jabung Regency. This study aims to determine the effect of Motivation and Job Satisfaction on Employee Performance at the Tanjung Jabung Barat District Education Office. Testing is done using multiple linear regression analysis. Hypothesis testing is done by using t test and $F$ test. The magnitude of the effect is $\mathrm{known}$ through testing the coefficient of determination. Based on the discussion it can be concluded that the effect of Motivation (X1) and Job Satisfaction (X2) together on Performance (Y) is 13.275\%. In the t test, the effect of Motivation (X1) and Job Satisfaction (X2) has a partial effect on Performance (Y). in the F test, Motivation (X1) and Job Satisfaction (X2) have a simultaneous influence on performance $(Y)$.
\end{abstract}

Keyword: Motivation; Job Satisfaction; Employee Performance

DOI: 10.33087 / ekonomis.v3i1.58

\section{PENDAHULUAN}

Pada umumnya setiap instansi dalam menjalankan kegiatan operasionalnya membutuhkan beberapa faktor yang mendukung untuk tercapainya kinerja yang baik dan produktifitas yang tinggi. Sumber daya manusia merupakan salah satu faktor terpenting, karena tanpa adanya peran dari sumber daya manusia yang berkualitas, segala aktifitas dalam suatu instansi tidak akan dapat terlaksana secara optimal. Setiap instansi harus menyadari berhasil atau tidaknya tugas dan fungsi yang dilaksanakan tergantung pada faktor sumber daya manusia (SDM). Sumber daya manusia yaitu orang-orang yang memberikan tenaga, bakat, kretifitas dan usahanya kepada organisasi, perusahaan atau instansi. Sarana dan prasarana yang dimiliki oleh suatu instansi tidak akan optimal pemanfaatannya tanpa ditunjang dengan kemampuan pegawai dalam penggunaan sarana dan prasarana yang ada (Adisetiawan, 2016)

Suatu instansi yang ingin melaksanakan tugas dan fungsinya dengan baik, maka dilakukan pengelolaan sumber daya manusia. Disamping lingkungan yang memadai dan didukung dengan fasilitas yang memadai dengan adanya tempat ibadah, toilet yang bersih dan nyaman, dapur kantor, tempat parkir yang teduh, Pengelolaan atau Manajemen sumber daya manusia memiliki peran dan fungsi yang sangat penting dalam setiap organisasi dan juga merupakan alat untuk mencapai tujuan yang diinginkan serta untuk memudahkan pencapaian organisasi agar dapat berdaya guna dan berhasil dengan secara maksimal (Adisetiawan dan Surono, 2016). Manajemen sumber daya manusia menurut Asnawi (2012) Personnel management is the planning, organiazing, directing and controling of the procurement, development, compensation, mantenance, and separation of human resources to the and that individual, organizational and societal objectives are accomplished. Manajemen personalia adalah perencanaan, pengorganisasian, pengarahan dan pengendalian dari pengadaan, pengembangan, kompensasi, pengintegrasian, pemeliharaan, dan pemberhentian karyawan, dengan maksud terwujudnya tujuan perusahaan, individu, karyawan dan masyarakat. Selanjutnya Asnawi (2012) menjelaskan Personnel administrason is the implementation of human resources (manpower) by and within an enterprise.

Pada dasarnya, kepuasan kerja merupakan merupakan hal yang bersifat individu. Setiap individu memiliki tingkat kepuasan yang berbeda-beda sesuai dengan sistem nilai-nilai yang berlaku pada dirinya. Ini disebabkan karena adanya perbedaan pada masing-masing individu. Semakin banyak aspek-aspek yang sesuai dengan keinginan individu tersebut, maka semakin tinggi tingkat kepuasan yang dirasakannya. Sebaliknya, jika semakin sedikit aspek-aspek dalam pekerjaannya yang tidak sesuai dengan keinginan individu tersebut, maka semakin rendah tingkat kepuasan yang dirasakan individu tersebut. Menurut Sutrisno (2009) yang menyatakan bahwa kepuasan kerja berhubungan erat dengan sikap dari karyawan terhadap pekerjaannya sendiri, situasi kerja, kerja sama antara pimpinan dengan para karyawan. 
Dinas Pendidikan Kabupaten Tanjung Jabung Barat merupakan unsur Pemerintah Kabupaten Tanjung Jabung Barat yang diberi tanggungjawab di bidang pendidikan, dipimpin oleh seorang Kepala Dinas yang berada di bawah dan bertanggung jawab kepada Bupati melalui Sekretaris Daerah sesuai dengan Peraturan Daerah Kabupaten Tanjung Jabung Barat Nomor 14 Tahun 2008 tentang Susunan Organisasi dan Tata Kerja Dinas Daerah Kabupaten Tanjung Jabung Barat dan Peraturan Bupati Tanjung Jabung Barat Nomor 9 Tahun 2008 tentang Uraian Tugas Pokok dan Fungsi Dinas Daerah Kabupaten Tanjung Jabung Barat. Untuk meningkatkan kinerja tersebut Dinas Pendidikan Kabupaten Tanjung Jabung Barat memberikan motivasi dan berusaha membuat para pegawainya merasa puas. Menurut Siagian (2002) bahwa motivasi adalah daya dorong yang dimiliki seseorang yang membuatnya mau dan rela untuk bekerja sekuat tenaga dengan mengerahkan segala kemampuan demi keberhasilan organisasi dalam mencapai tujuan.

\section{Tinjauan Pustaka Motivasi}

Motif seringkali diistilahkan sebagai dorongan. Dorongan atau tenaga tersebut merupakan gerak jiwa dan jasmani untuk berbuat, sehingga motif tersebut merupakan driving force yang menggerakkan manusia untuk bertingkah laku dan didalam perbuatannya itu mempunyai tujuan tertentu (As'ad, 2003). Motivasi secara sederhana dapat diartikan Motivating yang secara implisit berarti bahwa pimpinan suatu organisasi berada di tengah-tengah bawahannya, dengan demikian dapat memberikan bimbingan, instruksi, nasehat dan koreksi jika diperlukan (Siagian, 1995). Indikator motivasi kerja menurut Sedarmayanti (2004) yaitu antara lain sebagai berikut: Pekerjaan itu sendiri, Peluang untuk maju, Pengakuan atau penghargaan, Keberhasilan, Gaji (salary), Supervisi, Kebijakan dan Administrasi, Hubungan kerja, Kondisi kerja, dan Lingkungan Kerja

\section{Kepuasan Kerja}

Definisi kepuasan kerja dikemukakan Luthans yang dikutip Mariam (2009) adalah suatu keadaan emosi seseorang yang positif maupun menyenangkan yang dihasilkan dari penilaian suatu pekerjaan atau pengalaman kerja. Lima model kepuasan kerja, yang dikemukakan Kreitner \& Kinicki (2005) adalah; Pertama pemenuhan kebutuhan, model ini menjelaskan bahwa kepuasan ditentukan oleh karakteristik dari sebuah pekerjaan yang memungkinkan seseorang dapat memenuhi kebutuhannya. Kedua ketidakcocokan, model ini menjelaskan bahwa kepuasan adalah hasil dari harapan yang terpenuhi. Ketiga pencapaian nilai, model ini menjelaskan bahwa kepuasan berasal dari persepsi bahwa suatu pekerjaan memungkinkan untuk pemenuhan nilainilai kerja yang penting dari individu. Keempat persamaan, model ini kepuasan adalah suatu fungsi dari bagaimana seorang individu diperlakukan ditempat kerja. Kelima watak/genetik, model ini berusaha menjelaskan beberapa orang merasa puas dengan situasi dan kondisi kerja tertentu, namun sebagian lagi merasa tidak puas dengan kondisi tersebut.

Herzberg dengan teorinya tentang kepuasan kerja menyatakan bahwa kepuasan kerja berkaitan dengan faktor Motivator-Hygiene (Kreitner \& Kinicki, 2005). Faktor motivator berkaitan dengan pekerjaan yang menawarkan prestasi, pengakuan, pekerjaan yang menantang, tanggungjawab serta prospek kemajuan. Sedangkan faktor hygiene yang berkaitan kebijakan perusahaan, pengawasan, gaji, hubungan kerja dan kondisi kerja. Disimpulkan faktor hygiene hanya dapat mengeliminasi ketidakpuasan saja, tidak mampu untuk meningkatkan kepuasan kerja, sedangkan faktor motivator akan dapat meningkatkan kepuasan kerja, apabila faktor ini ada. Mas'ud (2004) merumuskan indikator-indikator kepuasan kerja dalam 5 indikator sebagai berikut : Kepuasan dengan gaji, Kepuasan dengan promosi, Kepuasan dengan rekan kerja, Kepuasan dengan penyelia, dan Kepuasan dengan pekerjaan itu sendiri. 


\section{Kinerja}

Menurut Mangkunegara (2000) Kinerja adalah hasil kerja secara kualitas dan kuantitas yang dicapai oleh seorang pegawai dalam melaksanakan tugasnya sesuai dengan tanggung jawab yang diberikan kepadanya. Menurut Gomes (2003) mengemukakan definisi kinerja pegawai sebagai ungkapan seperti output, efisiensi serta efektivitas sering dihubungkan dengan produktivitas. Sedangkan menurut Bernardin dalam Robbins (2002) kinerja konsep yang bersifat universal yang merupakan efektivitas operasional suatu organisasi, bagian organisasi dan bagian karyawannya berdasarkan standar dan kriteria yang telah ditetapkan sebelumnya, karena organisasi ada dasarnya dijalankan oleh manusia, maka kinerja sesungguhnya merupakan perilaku manusia dalam memainkanperan yang mereka lakukan dalam suatu organisasi untuk memenuhi standar perilaku yang telah ditetapkan agar membuahkan tindakan dan hasil yang diinginkan.

Ada beberapa indikator pengukuran kinerja pegawai menurut Gomes (2003) adalah sebagai berikut: (1) Quantity of work : Jumlah kerja yang dilakukan dalam suatu periode waktu yang ditentukan; (2) Quality of work : kualitas kerja yang dicapai berdasarkan syarat-syarat kesesuaian dan kesiapannya; (3) Job Knowledge : Luasnya pengetahuan mengenai pekerjaan dan keterampilannya; (4) Creativeness : Keaslian gagasan-gagasan yang dimunculkan dari tindakantindakan untuk menyelesaikan persoalan-persoalan yang timbul; (5) Cooperation : kesediaan untuk bekerja sama dengan orang lain (sesama anggota organisasi); (6) Dependability : Kesadaran dan dapat dipercaya dalam hal kehadiran dan penyelesaian kerja tepat pada waktunya; (7) Initiative : Semangat untuk melaksanakan tugas-tugas baru dan dalam memperbesar tanggung jawabnya; dan (8) Personal Qualities : Menyangkut kepribadian, kepemimpinan, keramah-tamahan, dan integritas pribadi.

\section{METODE}

Adapun objek penelitian dari penelitian ini adalah Kantor Dinas pendidikan Kabupaten Tanjung Jabung Barat. Populasi dalam penelitian ini adalah keseluruhan pegawai yang bekerja pada Kantor Dinas pendidikan Kabupaten Tanjung Jabung Barat yang tercatat yang berjumlah 80 orang. Untuk menentukan besarnya sampel yang akan dijadikan responden, peneliti mengacu pada pendapat Arikunto (2010). Arikunto dalam melakukan perhitungan ukuran sampel yang diperoleh menyatakan bahwa apabila populasi di bawah 100 maka diambil semuanya untuk dijadikan sampel. Tapi jika populasi di atas 100 maka diambil 10-25\%. Dalam hal ini populasi berjumlah 80 orang, maka sampel yang diambil sebesar 80 orang. Data primer adalah data yang diperoleh dengan cara penelitian dilapangan, yaitu data diperoleh dari para pegawai Kantor Dinas pendidikan Kabupaten Tanjung Jabung Barat dengan melakukan penyebaran kusioner. Data Sekunder adalah data yang diperoleh dengan cara mengadakan penelitian kepustakaan dan dokumen kepegawaian, dokumen kerja, dan dokumen lainnya yang berasal dari Kantor Dinas pendidikan Kabupaten Tanjung Jabung Barat Data-data yang didapat bersumber dari dalam (internal) Kantor Dinas pendidikan Kabupaten Tanjung Jabung Barat, seperti : data para pegawai, dan data lain yang mendukung. Sedangkan data eksternal bersumber dari literatur-literatur yang berkaitan dengan masalah yang diteliti.

Dalam memperoleh data, digunakan metode survey yaitu dengan menggunakan perangkat kuesioner terstruktur yang diajukan pada responden. Format kuesioner terdiri dari dua bagian utama, bagian pertama menyangkut pertanyaan-pertanyaan umum mengenai karakteristik pegawai dan bagian kedua berisi pertanyaan masalah pokok penelitian. Item-item pertanyaan diantaranya adalah seperti telah dikemukakan sebelumnya. Pengumpulan data dilakukan dengan pertama-tama meminta kesediaan para responden untuk berpartisipasi dalam penelitian ini, kemudian menyampaikan perangkat kuesioner penelitian untuk diisi oleh responden. 


\section{1) Path Analysis}

Untuk menjawab permasalahan menggunakan analisis jalur (Path Analysis) yang merupakan suatu metode pendekomposisian korelasi ke dalam bagian-bagian yang berbeda untuk menginterprestasikan suatu pengaruh/efek. Metode Path Analysis ini juga digunakan untuk menelaah hubungan antara model kausal yang dirumuskan atas dasar pertimbangan teoritis dan pengetahuan tertentu. Hubungan kausal selain didasarkan pada data, juga didasarkan pada pengetahuan, perumusan hipotesis dan analisis logis, sehingga dapat dikatakan Path Analysis ini dapat digunakan untuk menguji seperangkat hipotesis kausal serta untuk menafsirkan hubungan tersebut. Adapun hubungan struktural antar variabel motivasi dan kepuasan kerja terhadap kinerja dapat dijelaskan pada Gambar 1. PYX1 dan PYX2 adalah koefisien jalur dan $\mathrm{r}_{\mathrm{X} 1 \mathrm{X} 2}$ adalah koefisien korelasi, maka persamaan struktural untuk diagram jalur diatas dinyatakan dengan: $\mathrm{Y}=\mathrm{P}_{\mathrm{Yx} 1} \mathrm{X}_{1}+\mathrm{P}_{\mathrm{YX} 2} \mathrm{X}_{2}+\varepsilon$

Sedangkan pengaruh antar variabel diatas dinyatakan dengan persamaan sebagai berikut : Pengaruh X1 terhadap Y :

1.

Pengaruh langsung : $\mathrm{X}_{1} \rightarrow \mathrm{Y}=\left(\mathrm{P}_{\mathrm{YX} 1}\right) \times\left(\mathrm{P}_{\mathrm{YX} 1}\right)$

Pengaruh tidak langsung: $\mathrm{X}_{1} \Omega \mathrm{X}_{2} \rightarrow \mathrm{Y}=\left(\mathrm{P}_{\mathrm{YX} 1)} \mathrm{x}\left(\mathrm{r}_{\mathrm{X} 1 \mathrm{X} 2)} \mathrm{x}\left(\mathrm{P}_{\mathrm{YX} 2}\right)\right.\right.$

Pengaruh total : pengaruh langsung + pengaruh tidak langsung

2.

Pengaruh $\mathrm{X} 2$ terhadap $\mathrm{Y}$ :

Pengaruh langsung : $\mathrm{X}_{2} \rightarrow \mathrm{Y}=\left(\mathrm{P}_{\mathrm{YX} 2}\right) \times\left(\mathrm{P}_{\mathrm{YX} 2}\right)$

Pengaruh tidak langsung: $\mathrm{X}_{2}{ }^{\prime} \Omega \mathrm{X}_{1} \rightarrow \mathrm{Y}=\left(\mathrm{P}_{\mathrm{YX} 2}\right) \mathrm{x}\left(\mathrm{r}_{\mathrm{X} 1 \mathrm{X} 2)} \mathrm{x}\left(\mathrm{P}_{\mathrm{YX} 1)}\right.\right.$

Pengaruh total : pengaruh langsung + pengaruh tidak langsung

3.

$$
\mathrm{Y}=\mathrm{P}_{\mathrm{yx} 1}+\mathrm{P}_{\mathrm{yx} 2}+\varepsilon_{1}
$$

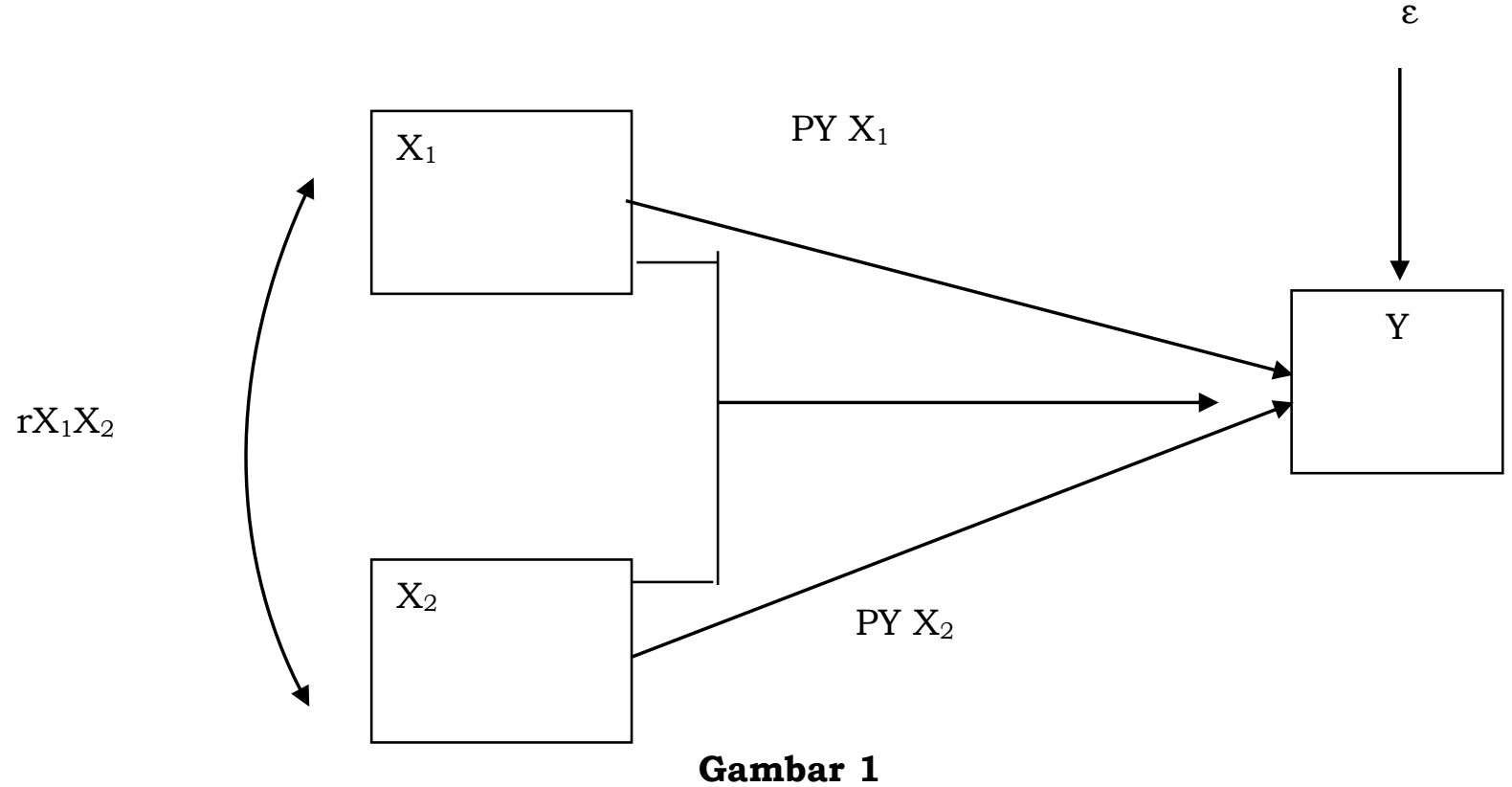

Hubungan Struktural Antara $X_{1}$ dan $X_{2}$ Terhadap $Y$

Keterangan : $\mathrm{X}_{1}$ : Motivasi; $\mathrm{X}_{2}$ : Kepuasan Kerja; $\mathrm{Y}$ : Kinerja

2) Uji t, uji t digunkan untuk mengkaji koefisien regresi secara individual yaitu antara variabel independen dengan variabel dependen. Adapun langkah-langkahnya sebagai berikut :

a. Menentukan Hipotesis 
HO : bi = 0, (Tidak ada pengaruh yang signifikan antara variabel independen $(\mathrm{x})$ terhadap variabel dependent (y))

$\mathrm{H} 1:$ bi $\neq 0$,(Ada pengaruh yang signifikan antara variabel independen $(\mathrm{x})$ terhadap variabel dependen (y))

b. Menentukan tingkat signifikansi

Diuji dengan tingkat signifikansi (a) sebesar 0.05.

c. Kesimpulan

HO diterima apabila $-\mathrm{t}$ tabel $<\mathrm{t}$ hitung $<\mathrm{t}$ tabel

HO di tolak apabila $\mathrm{t}$ hitung $>\mathrm{t}$ tabel atau $\mathrm{t}$ hitung $<-\mathrm{t}$ tabel.

3) Uji F, uji ini digunakan untuk mengetahui apakah seluruh variabel bebas secara simultan mempunyai pengaruh yang bermakna terhadap variabel terikatnya. Pengujian dilakukan dengan membandingkan nilai $F_{\text {hitung }}$ dengan $F_{\text {table }}$ pada derajat kesalahan 5\%. Apabila nilai $F_{\text {hitung }}>$ dari nilai $F_{\text {table, }}$, berarti bahwa variabel bebasnya secara simultan memberikan pengaruh yang bermakna terhadap variabel tergantungnya.

\section{HASIL}

Analisis Jalur Pengaruh Motivasi dan Kepuasan Kerja terhadap Kinerja

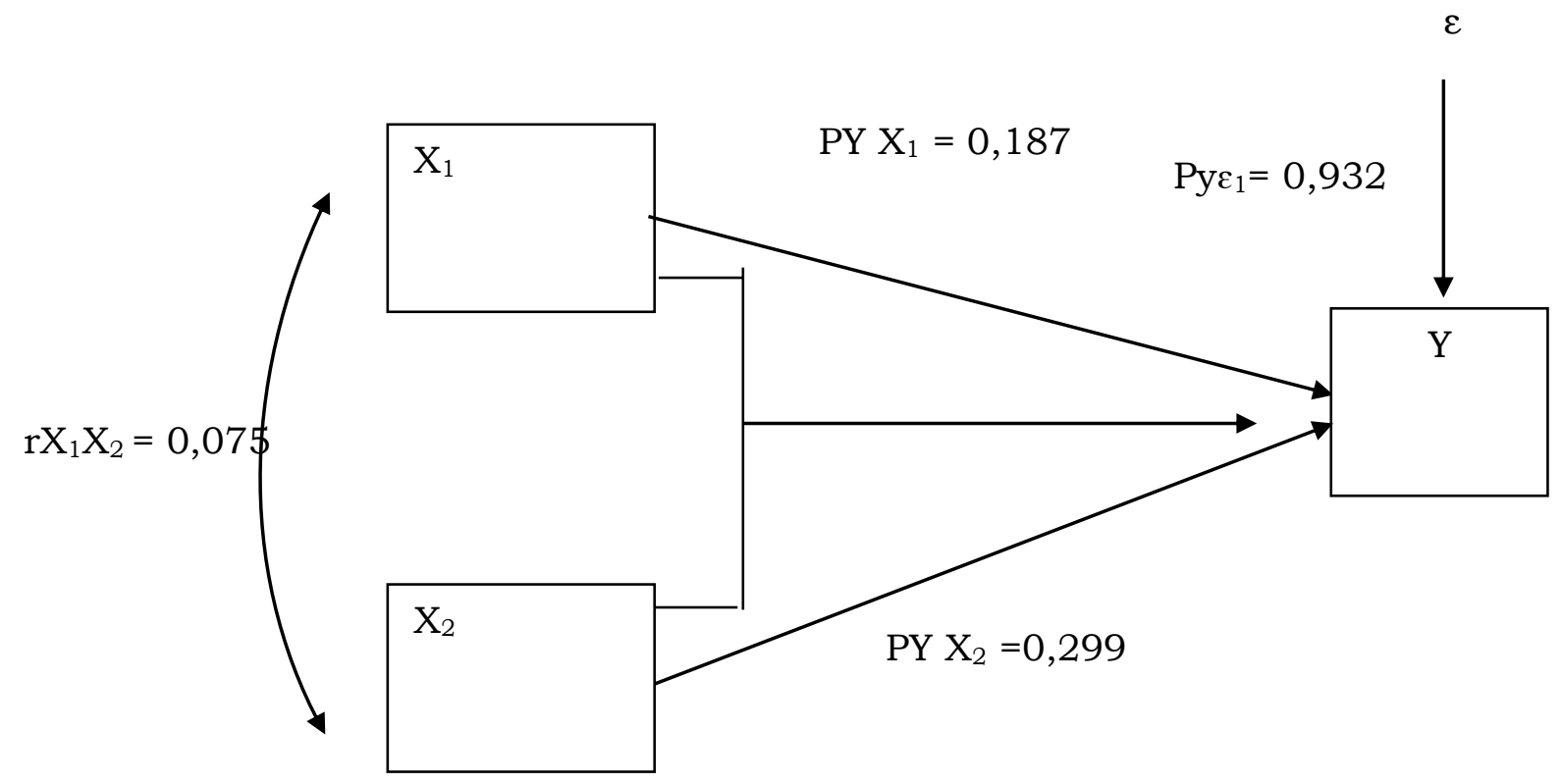

\section{Gambar 2 \\ Koefisien Jalur}

Pengaruh langsung Motivasi $\left(\mathrm{X}_{1}\right)$ terhadap Kinerja $(\mathrm{Y})$

$\mathrm{X}_{1} \rightarrow \mathrm{Y}=\left(\mathrm{pYX}_{1}\right) \quad\left(\mathrm{pYX}_{1}\right)=0,187 \times 0,187=0,03497=3,497 \%$

Pengaruh tidak langsung Motivasi $\left(\mathrm{X}_{1}\right)$ terhadap Kinerja $(\mathrm{Y})$ melalui Kepuasan Kerja $\left(\mathrm{X}_{2}\right)$

$\mathrm{X}_{1} \rightarrow \mathrm{Y} \Omega \mathrm{X}_{2}=\left(\mathrm{pYX}_{1}\right)\left(\mathrm{rx}_{1} \mathrm{x}_{2}\right)(\mathrm{pYX} 2)=0,187 \times 0,075 \times 0,299=0,00419=0,419 \%$

Total pengaruh langsung dan tidak langsung motivasi terhadap kinerja

$=0,03497+0,00419=0,0391=3,916 \%$

Rincian diatas pengaruh motivasi $\left(\mathrm{X}_{1}\right)$ terhadap kinerja $(\mathrm{Y})$ sebesar 3,916\% .

Pengaruh langsung Kepuasan $\left(\mathrm{X}_{2}\right)$ terhadap Kinerja $(\mathrm{Y})$

$\mathrm{X}_{2} \rightarrow \mathrm{Y}=\left(\mathrm{pYX}_{2}\right) \quad\left(\mathrm{pYX}_{2}\right)=0,299 \times 0,299=0,0894=8,94 \%$ 
Pengaruh tidak langsung Kepuasan Kerja $\left(\mathrm{X}_{2}\right)$ terhadap Kinerja $(\mathrm{Y})$ melalui Disiplin $\left(\mathrm{X}_{1}\right)$

$\left.\mathrm{X}_{2} \rightarrow \mathrm{Y} \Omega \mathrm{X}_{1}=\left(\mathrm{pYX}_{2}\right)\left(\mathrm{rX}_{2} \mathrm{X}_{1}\right)(\mathrm{pYX})_{1}\right)=0,299 \times 0,075 \times 0,187=0,00419=0,419 \%$

Total pengaruh langsung dan tidak langsung Kepuasan Kerja terhadap Kinerja

$=0,0894+0,00419=0,09359=9,359 \%$

Rincian diatas pengaruh Kepuasan Kerja $\left(\mathrm{X}_{2}\right)$ terhadap Kinerja $(\mathrm{Y})$ sebesar 8,5316\%

Pengaruh Motivasi (X1) dan Kepuasan Kerja $\left(\mathrm{X}_{2}\right)$ secara bersama-sama terhadap Kinerja $(\mathrm{Y})$

Pengaruh langsung Motivasi (X1) dan Kepuasan Kerja $\left(\mathrm{X}_{2}\right)$ secara bersama-sama terhadap Kinerja (Y)

$=\left(\mathrm{pYX}_{1}\right)\left(\mathrm{pYX}_{1}\right)+\left(\mathrm{pYX}_{2}\right) \quad\left(\mathrm{pYX}_{2}\right)=(0,187 \times 0,187)+(0,299 \times 0,299)=0,12437=12,437 \%$

Pengaruh tidak langsung Motivasi (X1) dan Kepuasan Kerja ( $\left.\mathrm{X}_{2}\right)$ secara bersama-sama terhadap Kinerja (Y).

$=\left(\mathrm{pYX}_{1}\right)\left(\mathrm{rx}_{2} \mathrm{x}_{1}\right)\left(\mathrm{pYX}_{2}\right)+(\mathrm{pYX})_{2}\left(\mathrm{rx}_{2} \mathrm{x}_{1}\right)\left(\mathrm{pYX}_{1}\right)=(0,299 \times 0,075 \times 0,187)+(0,299 \times 0,075 \times 0,187)=$ $0,00838=0,838 \%$

Total pengaruh Motivasi (X1) dan Kepuasan Kerja $\left(\mathrm{X}_{2}\right)$ secara bersama-sama terhadap Kinerja (Y) : $=0,12437+0,00838=0,13275=3,275 \%$

Rincian diatas pengaruh Motivasi (X1) dan Kepuasan Kerja $\left(\mathrm{X}_{2}\right)$ secara bersama-sama terhadap Kinerja (Y) sebesar 13,275\%.

Variabel Residu

$\mathrm{Py} \varepsilon_{1}=\sqrt{ } 1-\mathrm{R}^{2} \mathrm{Y}\left(\mathrm{X}_{1}, \mathrm{X}_{2}\right)=\sqrt{ } 1-0,132=0,965$

Jadi persamaan struktur adalah sebagai berikut:

$\mathrm{Y}=\mathrm{Pyx}_{1} \mathrm{X} 1+\mathrm{Pyx}_{2} \mathrm{X} 2+\varepsilon_{1}=0,187 \mathrm{X} 1+0,299 \mathrm{X} 2+0,965$

\section{Pengujian hipotesis}

Pengaruh motivasi terhadap kinerja yang ada membuktikan bahwa motivasi terhadap kinerja jika dilihat dari nilai $t$ hitung yaitu sebesar 1,754 dimana nilai $t$ tabel pada derajat kesalahan $5 \%$. sebesar 1,66488 ini dan tingkat signifikan sebesar 0,083 berarti variabel motivasi memberi pengaruh secara parsial terhadap variabel kinerja namun tidak signifikan. Selanjutnya, pengaruh kepuasan kerja terhadap kinerja yang ada membuktikan bahwa kepuasan kerja terhadap kinerja jika dilihat dari nilai t hitung yaitu sebesar 2,805 dimana nilai t tabel pada derajat kesalahan 5\%. sebesar 1,66488 ini dan tingkat signifikan sebesar 0,006 berarti variabel kepuasan kerja memberi pengaruh secara parsial dan signifikan terhadap variabel kinerja. Selanjutnya, jika dilihat dari nilai $\mathrm{F}$ hitung yaitu sebesar 5,872 dimana nilai $\mathrm{F}$ tabel dengan derajat kesalahan 5\% sebesar 3,12 berarti variabel disiplin dan motivasi mempengaruhi variabel kinerja secara bersamasama dan signifikan.

\section{SIMPULAN}

Berdasarkan pada pembahasan dapat ditarik kesimpulan bahwa pengaruh Motivasi (X1) dan Kepuasan Kerja $\left(\mathrm{X}_{2}\right)$ secara bersama-sama terhadap Kinerja (Y) sebesar 13,275\%. Pada uji t, pengaruh Motivasi (X1) dan Kepuasan Kerja $\left(\mathrm{X}_{2}\right)$ memiliki pengaruh secara parsial terhadap Kinerja (Y). pada uji F, Motivasi (X1) dan Kepuasan Kerja $\left(\mathrm{X}_{2}\right)$ memiliki pengaruh secara simultan terhadap kinerja $(\mathrm{Y})$.

\section{DAFTAR PUSTAKA}

Asnawi, Tetty, 2012 Pengaruh Budaya Organisasi, Kompetensi dan Komitmen Pegawai Terhadap Kepuasan Kerja Serta Implikasinya Terhadap Kinerja Pegawai Negeri Sipil (kasus Dinas dan Badan di Provinsi Jambi), Jurnal Manajemen, 16(1), 42-49

Adisetiawan, R., 2016, Faktor yang Mempengaruhi Lulusan SMA dalam Memilih Fakultas Ekonomi Program Studi Manajemen Universitas Batanghari, Jurnal Universitas Batanghari Jambi, 16(3), 1-11 
Adisetiawan, R., dan Surono., Yunan, 2016, Earnings Management and Accounting Information Value: Impact and Relevance., Business, Management and Economics Research, 2(10), 170179

As'ad, M. 2003. Psikologi Industri Seri Ilmu Sumber Daya Manusia. Edisi. Keempat. Yogyakarta

Fred, Luthans. 1998. Organizational Behavior: Instuctor's Resources Manual and Test Bank. New York: International Book Company

Fuad Mas'ud. 2004. Survei Diagnosis Organisasional. Semarang : Badan Penerbit Universitas Diponegoro

Gomes, Faustino Cardoso. 2003. Manajemen Sumber Daya Manusia. Yogyakarta : ANDI

Kreitner, Robert dan Kinicki, Angelo. 2005. Perilaku Organisasi. Jakarta: Salemba Empat

Mangkunegara Anwar.P (2000). Manajemen Kepegawaian Dan Sumber Daya Manusia, Bandung

Mariam, Rani. 2009. Pengaruh Gaya Kepemimpinan Dan Budaya Organisasi Terhadap Kinerja Karyawan Melalui Kepuasan Kerja Karyawan Sebagai Variabel Intervening Studi Pada Kantor Pusat PT.Asuransi Jasa Indonesia (Persero). Semarang : UNDIP

Robbins SP dan Judge. 2002. Perilaku Organisasi. Jakarta : Salemba Empat

Sutrisno, Edi. 2009. Manajemen Sumber Daya Manusia, Edisi pertama. Jakarta: Kencana Prenada Siagian, Sondang P., 2002, Fungsi-fungsi Manajerial, Bumi Aksara, Jakarta

Suharsimi, Arikunto. 2010. Prosedur Penelitian Suatu Pendekatan Praktik. Jakarta: Rineka Cipta

Sedarmayanti, Hj, 2004, Good Governance = Kepemerintahan yang Baik, Bandung: Mandar Maju 